\title{
Research on the Position-Pressure Master-Slave Control for a Rolling Shear Hydraulic Servo System
}

\author{
Wang Jun ${ }^{1}$ - Sun Binyu ${ }^{1, *}$ - Huang Qingxue ${ }^{1}$ - Li Hongzhou ${ }^{2}$ - Han Heyong1 \\ 1 Taiyuan University of Science and Technology, China \\ 2 Hebei WenFeng Iron and Steel Co., China
}

The position-pressure master-slave control of hydraulic servo system is a dual closed-loop system, which takes position closed loop as the main control system, pressure closed loop as the supplementary, bringing these two seemingly contradictory theories together while simultaneously control the system. When the position error value is bigger than the threshold value, the system will transfer the pressure signal to the signal which will be added to the position signal, and regulate the system. This paper first builds a mathematical model of the hydraulic servo system position-pressure master-slave control, then simulates the system with AMEsim and Matlab softwares, which verifies the feasibility of this function. Finally, experiments are conducted using the new function, and the results show that position-pressure master-slave control can improve the precision and stability of hydraulic servo system; this new function can also be applied to other high speed, high precision and heavy equipment.

Keywords: position control, pressure control, master-slave control-hydraulic servo system, simulation, dual closed-loop system

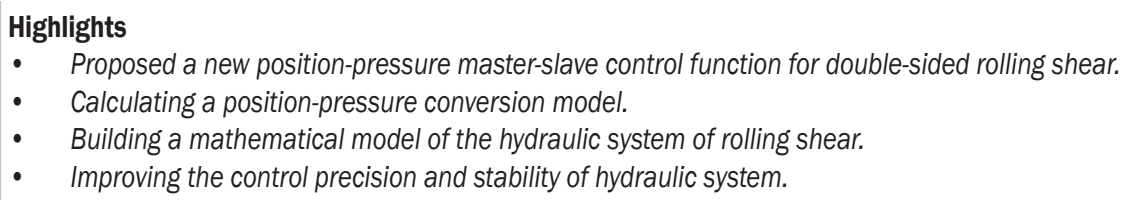

\section{INTRODUCTION}

Hydraulic double-sided rolling shear, the most advanced shearing machine, cuts off steel plates into a specified size [1], which is an important part of rolling production line and it will determine whether the quality of plates is good or not. Asymmetrical, valve controlling an asymmetrical cylinder (shown in Fig. 1) is the key to the hydraulic system of doublesided rolling shear, which uses a position-closed loop to make the cylinders move in order to ensure the rolling shear cutting off the steel plates according to the routine action.

Hydraulic rolling shear cuts off the steel plates with two cylinders moving harmonically along the given curve; the process is shown in Fig. 2. First, the left cylinder moves (shown as Fig. 2a). Then, when it moves to the designated place, the right cylinder begins to move (shown in Fig. 2b). Next, when the blade is moving to the place as shown in Fig. 2c, the rolling shear completes the action. Finally, the two cylinders retract to the initial position; a full action is completed, as shown in Fig. 2d. This equipment is simple, powerful, and highly reliable.

Usually, hydraulic rolling shear adopts position control to make the cylinder move along the specified curve, while (when shearing thick steel plates) the pressure of the two cavities of the cylinder is always

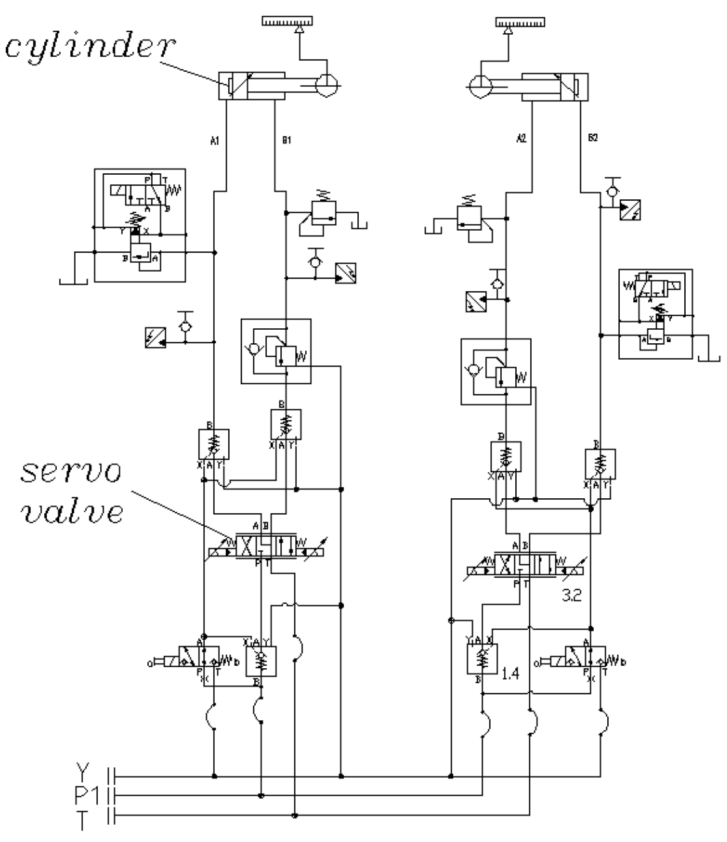

Fig. 1. The hydraulic scheme of hydraulic rolling shear

too low to push the upper blade moving along the desired curve to cut off the steel plates. As a result, the quality of the sheared plates will be poor (shown as Fig. 3). Therefore, how to improve the effect of controlling of rolling shear is a widely studied issue 

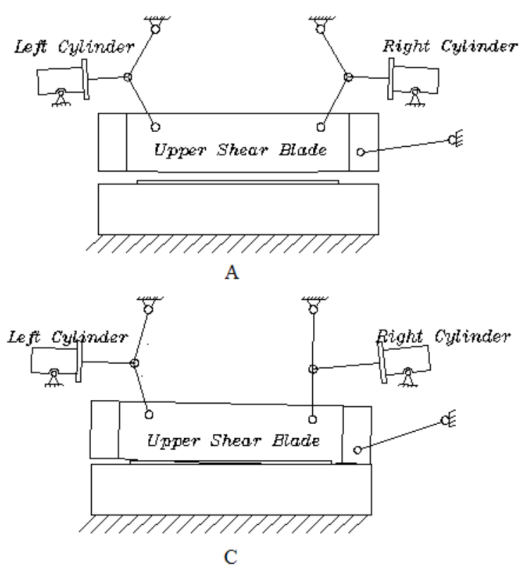

$\mathrm{C}$
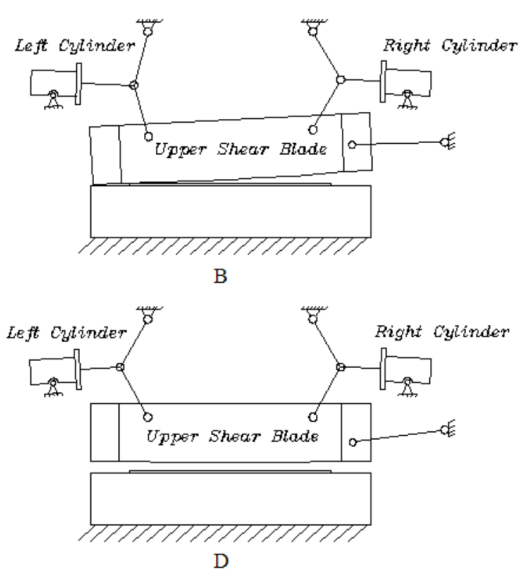

$\mathrm{D}$

Fig. 2. The shearing process of hydraulic rolling shear

[2]. Some researchers want to improve the structure of the rolling shear. Huang et al. design a new mechanism [3], which is powerful but heavy. Optimizing the mechanism of rolling shear cannot solve the problem of powerless; some researchers propose new control algorithms to improve the performance of the position control: Quan and Xu [4] put forward a new control method combining pressure and position in series and parallel, while Madani and Moallem [5] propose position/force control, but both of them are unstable when switching the pressure either to position control or position to pressure control. Bessa et al. [6] put forward a new type of control using sliding mode control, while Kim et al. [7] use QFT to perfect the position control. These are too complex to apply to the production in factories.

This paper puts forward a new control method: pressure-position master-slave control for doublesided rolling shear, which takes the position closed loop as the main control system, and the pressure closed loop as supplementary. This new function can make the cylinder move along the desired curves and will not be affected by the external loads, so the shape of the sheared plates will be improved. It has both theoretical significance and practical significance for improving the control precision and performance of heavy and high-speed equipment.
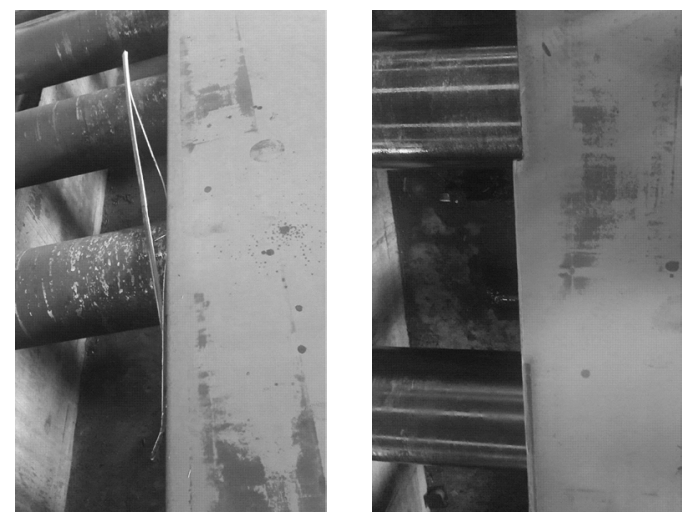

Fig. 3. Defect of steel plate

\section{BUILD THE MATH MODEL}

The structure diagram of position-pressure masterslave control is shown in Fig. 4.

The pressure signal from cylinder is detected by the pressure sensors and sent to the pressure-position conversion model; the master-slave controller will

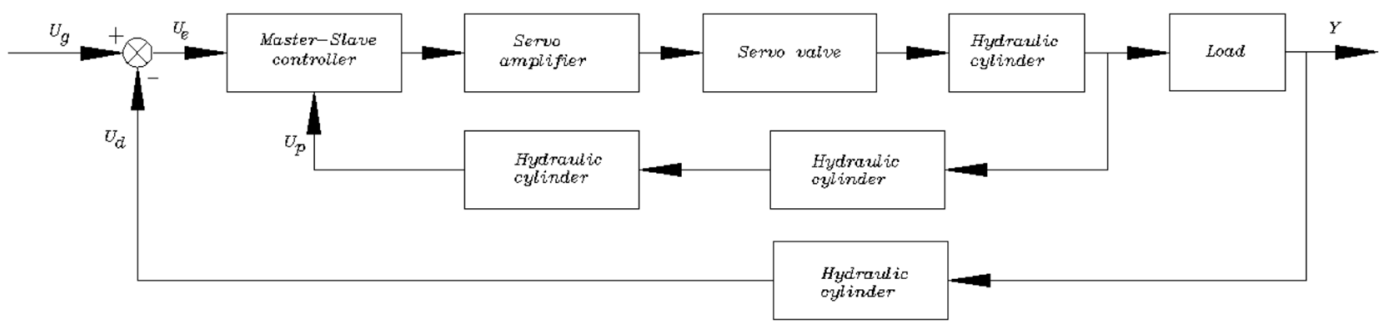

Fig. 4. Structure diagram of position-pressure master-slave control 
then judge when the pressure signal will be added to the position signal, if the position signal error is bigger than the threshold, the pressure closed loop is connected, the converted pressure signal is a compensation for the position signal to adjust the input signal, rapidly enlarging the flow of servo valve, and accelerating the speed of cylinder, so the position error of cylinder will be small, the pressure and position of cylinder will be in control. Meanwhile, the position control will not be affected by the pressure control. Thus, this new function can simultaneously control the position and the pressure of the cylinder.

The schematic of the asymmetrical servo valve controlling asymmetrical cylinder is shown in Fig. 4. This paper researches the mathematical model when the blade begins to contact the steel plates, $F_{L}$ is a constant, the equilibrium equation for the servo cylinder and the loads at two adjacent moments, which are the beginning and ending points of the shortest time that the pressure sensor can obtain:

$$
\begin{gathered}
A_{1} p_{t-1}=m_{t} a_{t-1}+B_{p} \dot{x}_{t-1}+K x_{t-1}+F_{L}, \\
A_{1} p_{t}=m_{t} a_{t}+B_{p} \dot{x}_{t}+K x_{t}+F_{L} .
\end{gathered}
$$

Eq. (3) is subtracted from Eq. (2) to Eq. (1):

$$
\frac{X_{t}-X_{t-1}}{P_{t}-P_{t-1}}=\frac{A_{1}}{K}-\frac{M_{t}\left(A_{t}-A_{t-1}\right)}{P_{t}-P_{t-1}}-\frac{B_{p}\left(V_{t}-V_{t-1}\right)}{P_{t}-P_{t-1}} .
$$

When shearing the plates, $M_{t}\left(A_{t}-A_{t-1}\right)$ and $B_{p}\left(V_{t}-V_{t-1}\right)$ will be ignored because the accelerated speed and speed are changing so small.

The simplified Eq. (3) is shown as Eq. (4).

$$
K_{t}=\frac{X_{t}-X_{t-1}}{P_{t}-P_{t-1}}=\frac{A_{1}}{K}
$$

Thus, the computation formula of positionpressure conversion coefficient is shown as Eq. (5):

$$
K_{t}=\left|\frac{\Delta X}{\Delta P}\right|=\left|\frac{X_{t}-X_{t-1}}{P_{t}-P_{t-1}}\right|,
$$

where $K_{t}$ is the position-pressure conversion gain, $\Delta P$ is the difference in pressure between two moments, $\Delta X$ is the difference in position between two moments, $X_{t}$ is the position signal of cylinder at NO.t moment, $X_{t-1}$ is the position signal of cylinder at NO.t-1 moment, $P_{t}$ is the pressure signal of cylinder at NO.t moment, and $P_{t-1}$ is the pressure signal of cylinder at NO.t-1 moment.

When the upper blade begins to contact the steel plate, the equilibrium equation is shown as Eq. (6):

$$
p_{1} A_{1}-p_{2} A_{2}=F_{L},
$$

where $p_{1}$ is the pressure of the blind end of the cylinder, $p_{2}$ is the pressure of the rod end of the cylinder, $A_{1}$ is the area of the piston, $A_{2}$ is the area of the piston rod, and $F_{L}$ is the load of servo cylinder.

The positive direction is where the rod stretches out, the pressure of system load is $P_{L}$, flow is $q_{L}$ :

$$
P_{L}=\frac{F_{L}}{A_{1}},
$$

and $F_{L}=P_{1} A_{1}-P_{2} A_{2}$.

So, the Eq. (7) can be transferred to be:

$$
P_{L}=\frac{F_{L}}{A_{1}}=\frac{P_{1} A_{1}-P_{2} A_{2}}{A_{1}}=P_{1}-P_{2} \frac{A_{2}}{A_{1}}=P_{1}-\lambda P_{2},
$$

where $\lambda=\frac{A_{2}}{A_{1}}$.

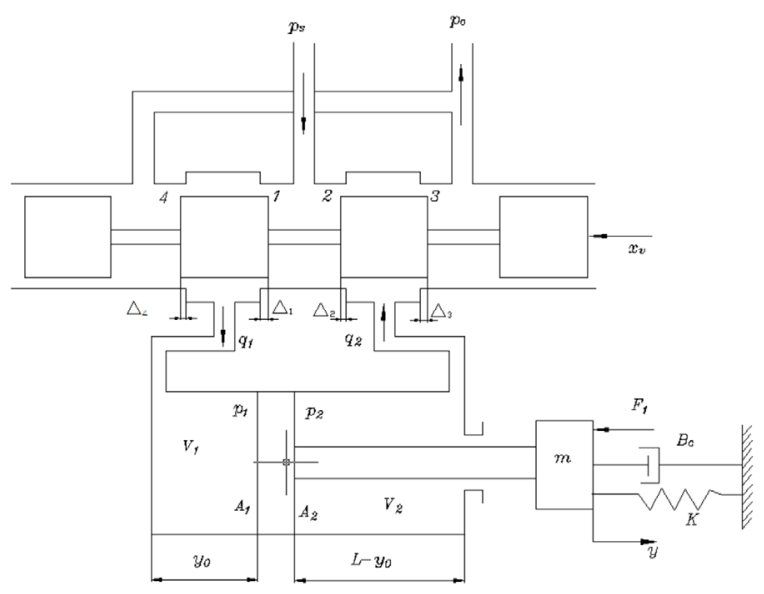

Fig. 5. The schematic of servo asymmetrical controlling asymmetrical cylinder

The flow equation of the valve is:

$$
q_{L}=K_{q} x_{v}-K_{c} p_{L} .
$$

Because this system uses asymmetrical valve to control asymmetrical cylinder, the flow gain $K_{q}$ and flow-pressure coefficient $K_{c}$ are shown as following:

$$
\begin{gathered}
K_{q}=\frac{\partial q_{L}}{\partial x_{v}}=C_{d} w_{1} \sqrt{\frac{2\left(p_{s}-p_{1}\right)}{\rho(1+\lambda)}}, \\
K_{c}=\frac{\partial q_{L}}{\partial p_{L}}=\frac{C_{d} w_{1}}{\sqrt{2 \rho(1+\lambda)\left(p_{s}-p_{1}\right)}} .
\end{gathered}
$$

Assuming that the connect pipelines between servo valve and cylinder are short, symmetric and thick; the pressure loss due to frictional resistance 
and dynamic effect of pipe are ignored; the oil bulk modulus and the oil temperature are constants; the internal and external leakage are laminar flow.

According to Fig. 5, the flow into the cylinder is $q_{1}$ out of cylinder is $q_{2}$, so, the flow equations are:

$$
\begin{aligned}
& q_{1}=\frac{d V_{1}}{d t}+C_{i p}\left(p_{1}-p_{2}\right)+C_{e p} p_{1}+\frac{V_{1}}{\beta_{e}} \frac{d p_{1}}{d t}, \\
& q_{2}=\frac{d V_{2}}{d t}+C_{i p}\left(p_{1}-p_{2}\right)+C_{e p} p_{2}+\frac{V_{2}}{\beta_{e}} \frac{d p_{2}}{d t},
\end{aligned}
$$

where $V_{1}$ is the effective volume of the blind end of the cylinder, $V_{2}$ is the effective volume of the rod end of the cylinder, $C_{i p}$ is the internal leakage coefficient, $C_{e p}$ is the external leakage coefficient, and $\beta_{e}$ is the oil bulk modulus of elasticity.

The volumes of the cavities of cylinder in the initial state are $V_{10}$ and $V_{20}$. When the piston of the cylinder is moving $x_{p}$, the equations are as follows:

$$
\begin{aligned}
& V_{1}=V_{10}+A_{1} x_{p}, \\
& V_{2}=V_{20}+A_{2} x_{p},
\end{aligned}
$$

and

$$
\begin{gathered}
\frac{d V_{1}}{d t}=A_{1} \frac{d x_{p}}{d t}, \\
\frac{d V_{2}}{d t}=-A_{2} \frac{d x_{p}}{d t}=-A_{1} \frac{d x_{p}}{d t} .
\end{gathered}
$$

The flow of cylinder is shown as following:

$$
q_{L}=q_{1}+\lambda q_{2} .
$$

Put Eqs. (10) to (15) into (18), and simplify it:

$$
\begin{aligned}
& q_{L}=q_{1}+\lambda q_{2}=C_{i p}\left(p_{1}-p_{2}\right)(1+\lambda)+ \\
& +C_{e p}\left(p_{1}-\lambda p_{2}\right)+\left(1+\lambda^{2}\right) A_{1} \frac{d x_{p}}{d t}+\frac{V_{10}}{\beta_{e}} \frac{d p_{1}}{d t}- \\
& -\lambda \frac{V_{20}}{\beta_{e}} \frac{d p_{2}}{d t}+\frac{A_{1} x_{p}}{\beta_{e}}\left(\frac{d p_{1}}{d t}+\lambda^{2} \frac{d p_{2}}{d t}\right) .
\end{aligned}
$$

The cylinder flow continuity equation can be obtained by linearizing Eq. (19) :

$$
q_{L}=A_{1} \frac{d x_{p}}{d t}+C_{t p} p_{L}+\frac{V_{t}}{2\left(1-\lambda^{2}\right) \beta_{e}} \frac{d p_{L}}{d t},
$$

where: $C_{t p}$ is the leakage coefficient of cylinder and

$$
C_{t p}=\frac{1+\lambda}{1-\lambda^{2}} C_{i p}+\frac{1}{1-\lambda^{2}} C_{e p}
$$

Equilibrium equation between cylinder and load [8] to [10] is Eq. (21):

$$
A_{1} p_{1}-A_{2} p_{2}=m_{t} \frac{d^{2} x_{p}}{d t^{2}}+B_{p} \frac{d x_{p}}{d t}+K x_{p}+F_{L}
$$

and $A_{2}=\lambda A_{1}$, the left of the Eq. (21) can be simplified as: $A_{1} p_{1}-A_{2} p_{2}=A_{1}\left(p_{1}-\lambda p_{2}\right)=A_{1} p_{L}$.

Then, we arrive at the Eq. (22) [11] to [13]:

$$
A_{1} p_{L}=m_{t} \frac{d^{2} x_{p}}{d t^{2}}+B_{p} \frac{d x_{p}}{d t}+K x_{p}+F_{L}
$$

where $m_{t}$ is the total mass of piston and loads refferred to piston, $B_{p}$ is the viscosity damping coefficient, $K$ is the spring stiffness of the load, and $F_{L}$ is the external load.

Eqs. (9), (20) and (22) are Laplace transformed [14]:

$$
Q_{L}=K_{q} X_{v}-K_{c} P_{L}
$$

$$
\begin{gathered}
Q_{L}=A_{1} s X_{p}+C_{t p} P_{L}+\frac{V_{t}}{2\left(1-\lambda^{2}\right) \beta_{e}} s P_{L}, \\
A_{1} p_{L}=m_{t} s^{2} X_{p}+B_{p} s X_{p}+K X_{p}+F_{L} .
\end{gathered}
$$

According to the equations above, the transfer function of the servo cylinder can be obtained, Eq. (25a):

$$
X_{p}=\frac{\frac{K_{q}}{A_{1}} X_{v}-\frac{K_{c e}}{A_{1}^{2}}\left(1+\frac{V_{t}}{2\left(1-\lambda^{2}\right) \beta_{e} K_{c e}}\right) F_{L}}{\frac{m_{t} V_{t}}{2\left(1-\lambda^{2}\right) \beta_{e} A_{1}^{2}} s^{3}+\left(\frac{K_{c e} m_{t}}{A_{1}^{2}}+\frac{V_{t} B_{p}}{2\left(1-\lambda^{2}\right) \beta_{e} A_{1}^{2}}\right) s^{2}+\left(1+\frac{B_{p} K_{c e}}{A_{1}^{2}}+\frac{K V_{t}}{2\left(1-\lambda^{2}\right) \beta_{e} A_{1}^{2}}\right) s+\frac{K K_{c e}}{A_{1}^{2}}} .
$$


The gain of position sensor is [15]:

$$
K_{d}=\frac{U_{d}}{Y},
$$

where $U_{d}$ is the output of the position closed loop.

The transfer function of slave pressure control is:

$$
\begin{gathered}
U_{p}=P_{L} \cdot K_{P} \cdot K_{t}, \\
U_{e}=U_{g}-U_{P}-U_{d},
\end{gathered}
$$

where $U_{P}$ is the output of slave pressure control, $K_{P}$ is the gain of the pressure sensor, and $K_{t}$ is the positionpressure conversion coefficient.

\section{SIMULATIONS}

This paper uses AMEsim software to simulate the hydraulic system of rolling shear, and SIMULINK software to simulate its control system. The hydraulic system model of rolling shear in AMEsim is shown in Fig. 6, and the control system in SIMULINK is shown in Fig. 7.

The system parameters in the simulation model are shown in Table 1.

First, only the position closed loop is used in the simulation system. The position and pressure curves are shown in Fig. 8, which indicates that when the

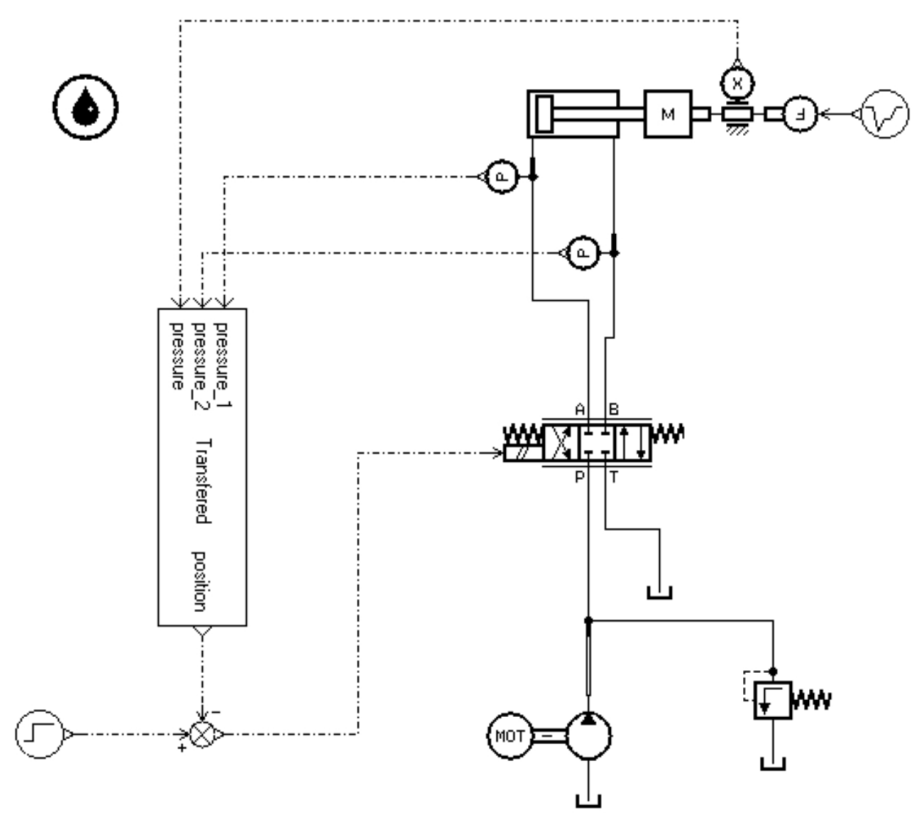

Fig. 6. The hydraulic system model in AMEsim

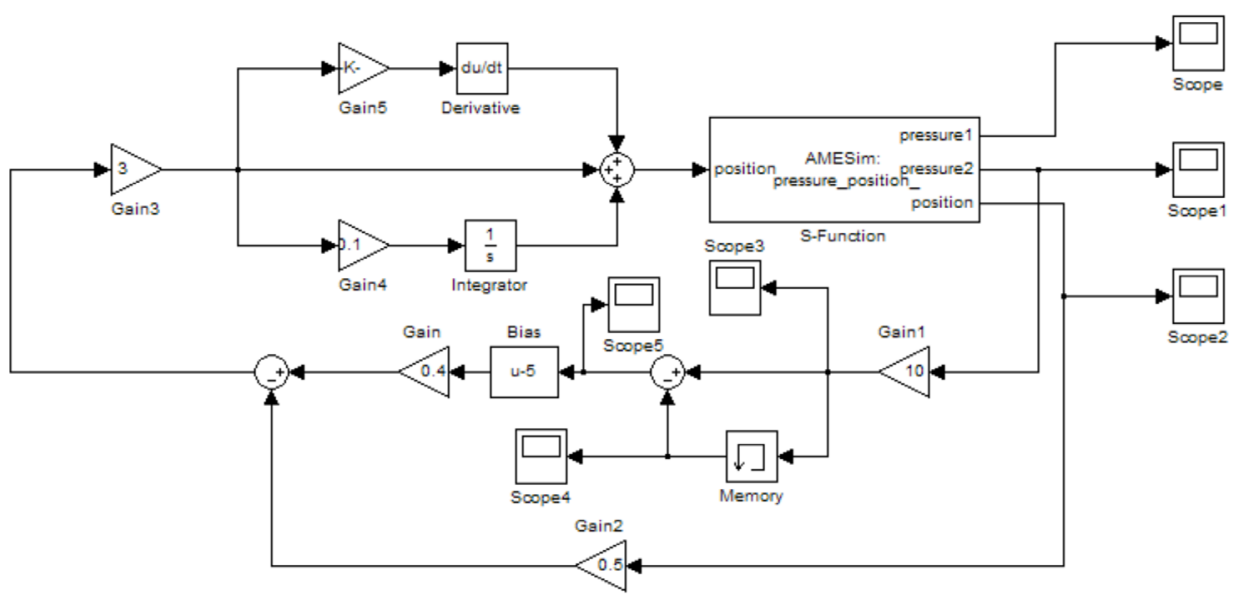

Fig. 7. The control system model in SIMULINK 
external load is changing fast, the pressure will lag behind, and the cylinder cannot move along with the given curve, so that the rolling shear is not able to cut off the steel plates.

Table. 1. Parameters of the system

\begin{tabular}{|c|c|c|c|}
\hline Working pressure & $28 \mathrm{MPa}$ & Oil elastic modulus & 14000 \\
\hline $\begin{array}{l}\text { Parameters of } \\
\text { cylinder }\end{array}$ & $\begin{array}{r}510 / 380 \\
\mathrm{~mm}\end{array}$ & Cylinder stroke & $477 \mathrm{~mm}$ \\
\hline Oil density & $900 \mathrm{~kg} / \mathrm{m}^{3}$ & Dynamic mass & $17000 \mathrm{~kg}$ \\
\hline $\begin{array}{l}\text { Frequency respon- } \\
\text { se of servo valve }\end{array}$ & $35 \mathrm{~Hz}$ & $\begin{array}{l}\text { Flow P-A of servo } \\
\text { valve }\end{array}$ & $1000 \mathrm{~L} / \mathrm{min}$ \\
\hline $\begin{array}{l}\text { Pressure drop of } \\
\text { servo valve }\end{array}$ & $0.5 \mathrm{MPa}$ & $\begin{array}{l}\text { Flow B-T of servo } \\
\text { valve }\end{array}$ & $500 \mathrm{~L} / \mathrm{min}$ \\
\hline $\begin{array}{l}\text { Damping ratio of } \\
\text { servo valve }\end{array}$ & 0.8 & $\begin{array}{l}\text { Flow A-T of servo } \\
\text { valve }\end{array}$ & $1000 \mathrm{~L} / \mathrm{min}$ \\
\hline $\begin{array}{l}\text { Rated current of } \\
\text { servo valve }\end{array}$ & $40 \mathrm{~mA}$ & $\begin{array}{l}\text { Flow P-B of servo } \\
\text { valve }\end{array}$ & $500 \mathrm{~L} / \mathrm{min}$ \\
\hline Gain 1 & 10 & Gain 2 & 0.5 \\
\hline Gain 3 & 3 & Gain 4 & 0.1 \\
\hline Gain 5 & 0.01 & Gain & 4 \\
\hline $\begin{array}{l}\text { Flow gain of the } \\
\text { servo valve }\end{array}$ & $1.7 \mathrm{~m}^{2} / \mathrm{s}$ & $\begin{array}{l}\text { Flow-pressure gain } \\
\text { of the servo valve }\end{array}$ & $\begin{array}{r}2.1 \times 10^{-12} \\
\mathrm{~m}^{5} / \mathrm{N} \times \mathrm{s}\end{array}$ \\
\hline
\end{tabular}

Fig. 9 shows the position and pressure curves when using position-pressure master-slave control, which indicates that the new function makes the system react fast and the position curve can follow the track of the given curve perfectly.

The results indicate that the cylinder can move along with the given curve using position-pressure master-slave control, and the pressure of the cylinder is stable, which is not affected by the external load. Thus, the pressure-position master-slave control can improve the precision and the stability of the hydraulic servo system.

\section{EXPERIMENTS}

The experiments are conducted on experimental double-sided rolling shear. The sheared steel plates are $30 \mathrm{~mm}$ in thick, $2100 \mathrm{~mm}$ in width. First, the experiments are conducted with the position closed loop only, and then using the position-pressure master-slave control instead. Finally, comparing the curves obtained by these two functions, the merits and demerits are analyzed. The servo valve used is 4WRTE32 produced by Rexroth; the pressure sensor used is HDA3840-A-400-000 produced by HYDAC.

Table 2 is the experimental data using the closed loop position only, and the Fig. 10 is the position
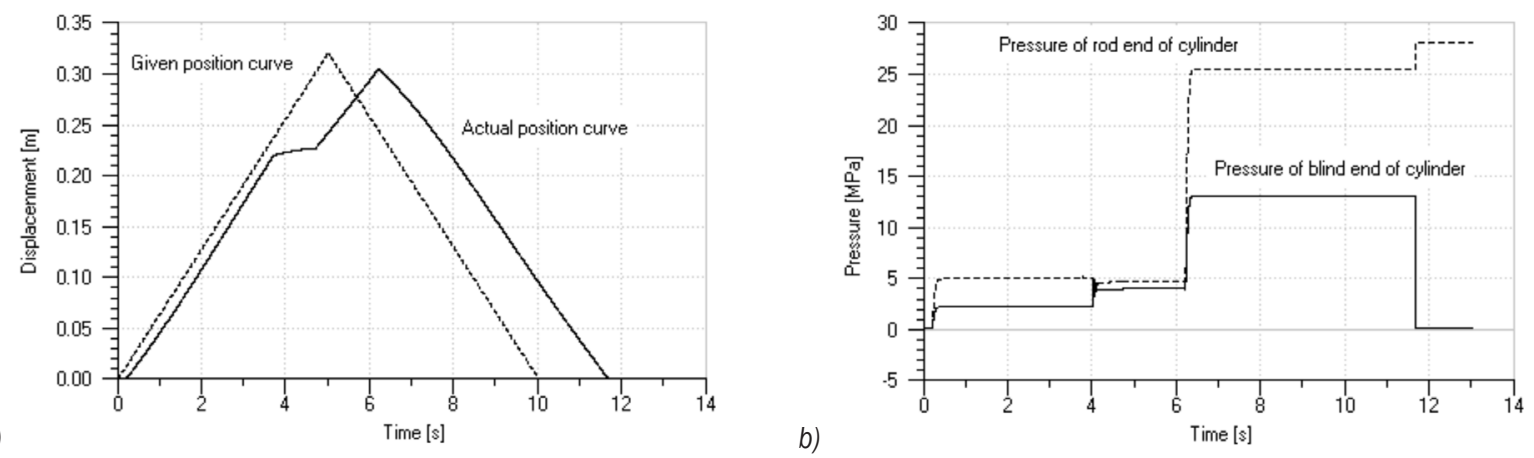

Fig. 8. a) The position curves and b) the pressure curves using position closed loop only
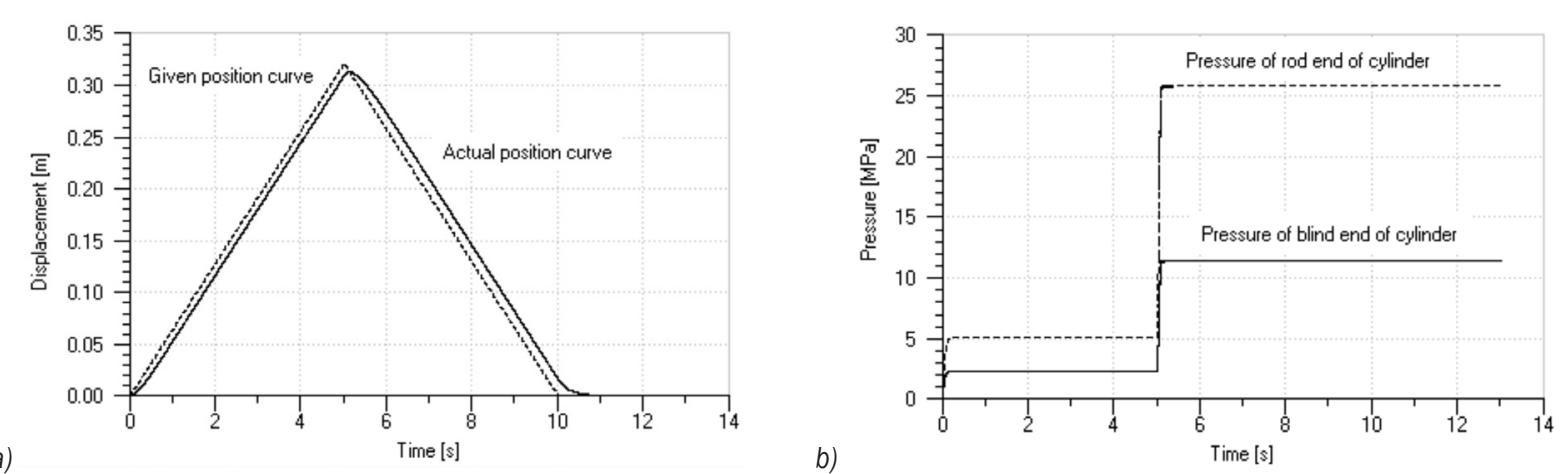

Fig. 9. a) The position curves and b) the pressure curves using position-pressure master-slave control 
curves and pressure curves fitted by software Origin according to the experimental data.

Table 2. Experiment data

\begin{tabular}{ccccc}
\hline $\begin{array}{c}\text { Time } \\
{[\mathrm{s}]}\end{array}$ & $\begin{array}{c}\text { Given } \\
\text { displacement } \\
{[\mathrm{mm}]}\end{array}$ & $\begin{array}{c}\text { Actual } \\
\text { displacement } \\
{[\mathrm{mm}]}\end{array}$ & $\begin{array}{c}\text { The rod } \\
\text { end of the } \\
\text { cylinder } \\
{[\mathrm{mm}]}\end{array}$ & $\begin{array}{c}\text { The blind } \\
\text { end of the } \\
\text { cylinder } \\
{[\mathrm{mm}]}\end{array}$ \\
\hline 0 & 0 & 0 & 4.935 & 8.498 \\
\hline 1 & 71.314 & 69.091 & 9.262 & 8.276 \\
\hline 2 & 164.937 & 157.841 & 8.741 & 9.960 \\
\hline 3 & 264.411 & 207.361 & 7.010 & 10.001 \\
\hline 4 & 320 & 310.491 & 6.114 & 11.170 \\
\hline 5 & 237.714 & 263.194 & 6.946 & 10.539 \\
\hline 6 & 144.457 & 169.937 & 8.741 & 10.112 \\
\hline 7 & 61.074 & 76.314 & 9.262 & 8.276 \\
\hline 8 & 0 & 8.113 & 5.351 & 7.302 \\
\hline
\end{tabular}

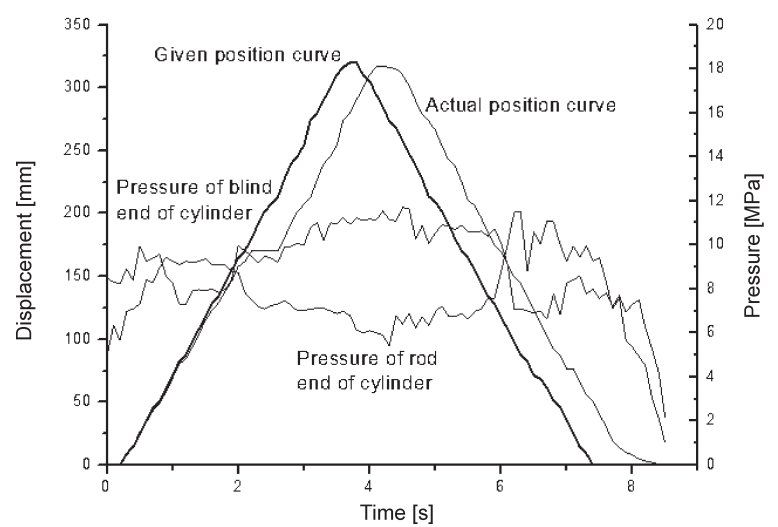

Fig. 10. The position and pressure curves of rolling shear with position closed loop only

Table 2 and Fig. 10 show that the actual position curve is defective; at about $2.3 \mathrm{~s}$, the actual position curve is seriously deflected from the given position curve, the biggest error of position is $32 \mathrm{~mm}$, and the pressure fluctuation is about 2.1 $\mathrm{MPa}$.

Table 3. Experiment data

\begin{tabular}{ccccc}
\hline $\begin{array}{c}\text { Time } \\
{[\mathrm{s}]}\end{array}$ & $\begin{array}{c}\text { Given } \\
\text { displacement } \\
{[\mathrm{mm}]}\end{array}$ & $\begin{array}{c}\text { Actual } \\
\text { displacement } \\
{[\mathrm{mm}]}\end{array}$ & $\begin{array}{c}\text { The rod } \\
\text { end of the } \\
\text { cylinder } \\
{[\mathrm{mm}]}\end{array}$ & $\begin{array}{c}\text { The blind } \\
\text { end of the } \\
\text { cylinder } \\
{[\mathrm{mm}]}\end{array}$ \\
\hline 0 & 0 & 0.264 & 4.9347 & 10.498 \\
\hline 1 & 71.314 & 69.21 & 9.262 & 8.2764 \\
\hline 2 & 164.937 & 163.18 & 9.7412 & 9.9609 \\
\hline 3 & 264.411 & 262.832 & 6.2698 & 11.7554 \\
\hline 4 & 320 & 320.424 & 5.9774 & 12.8276 \\
\hline 5 & 237.714 & 241.722 & 6.9641 & 11.845 \\
\hline 6 & 144.457 & 141.964 & 10.8895 & 6.982 \\
\hline 7 & 61.074 & 59.064 & 10.4502 & 8.594 \\
\hline 8 & 0 & 0.125 & 4.502 & 6.215 \\
\hline
\end{tabular}

Then, the pressure closed loop is added to the system, using the position-pressure master-slave control. Table 3 shows data from laboratory, and the Fig. 11 shows position and pressure curves according to the data with the new method proposed in this paper.

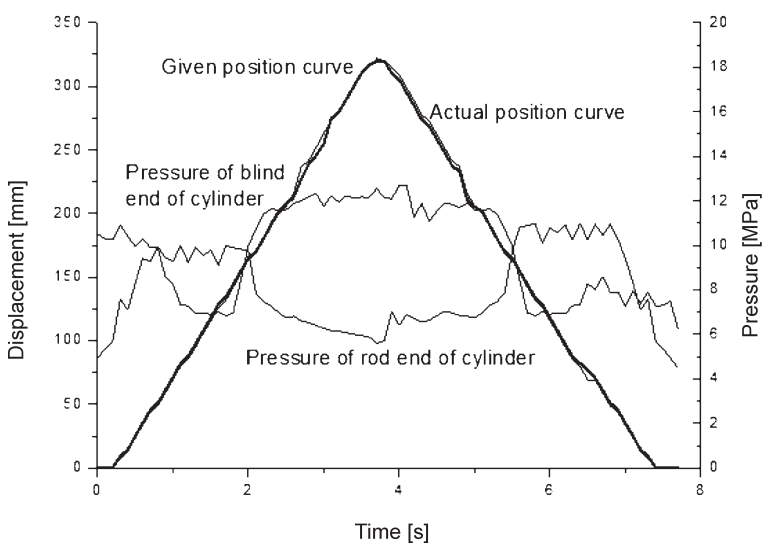

Fig. 11. Position and pressure curves

Table 3 shows the data of given displacement, actual displacement, pressure of the blind end of the cylinder and the pressure of the rod end of the cylinder in a whole process of rolling shear. Fig. 11 and Table 3 indicate that the biggest error between actual displacement and given displacement is $3 \mathrm{~mm}$, the pressure fluctuation is less than what in which uses the closed loop position only. Compared to the results in Fig. 10, the position curve in Fig. 11 is perfect, and the following performance is better, so the rolling shear can cut off the steel plate to a level of quality that meets the standards of industrial production.

Simply put, when double-sided rolling shear using position-pressure master-slave control to cut off the steel plates, the position curve of the cylinder can follow the calculated curves well, the pressure is stable, the quality of sheared plates and the production efficiency are both improved, which can meet the demands of clients. Position-pressure master-slave control can improve the precision of the position and pressure of cylinider, making the rolling shear cut thicker plates.

\section{CONCLUSIONS}

Based on a practical issue, for solving the problems when the rolling shear cuts the steel plates, this paper puts forward a new position-pressure master-slave control function, which can improve the precision of position and pressure; putting these two seemingly contradictory theories together and improving the 
quality of steel plates. This paper builds a mathematical model of the hydraulic system of rolling shear, and then simulates the hydraulic system by using AMEsim and SIMULINK; the results indicate that the new theory can be applied to practice. Experiments are conducted; the pressure curves and position curves obtained via simulation and experiment show that the position-pressure master-slave control is feasible and verify the theory put forward by this paper has practical value.

The position-pressure master-slave control proposed in this paper improves the anti-jamming capability, precision and stability of the system; thickness of sheared steel plates is increased by $35 \%$ and the quality also be improved. It is easy to use in the plants and with other hydraulic servo systems with high speed, massive flows and heavy loads.

\section{ACKNOWLEDGEMENT}

This paper was supported by Technology Innovation Project for Postgraduate of Taiyuan University of Science and Technology (20134023); Ph.D. Programs Foundation of Ministry of Education of China (20111103); The Initial Funding of Doctor Research of Taiyuan University of Science and Technology (20122047); Provincial Fund for Young Scholars (2013021019-2), Provincial Fund for Technological Innovation (2013101013).

\section{REFERENCES}

[1] Han, H. Y., Huang, Q. X., Wang, J., Wang, J. (2013). The analysis of new hydraulic rolling shear servo system dynamic characteristics. Proceedings of the Institution of Mechanical Engineers, Part B: Journal of Engineering Manufacture, vol. 227, no. 3, p. 453-459, DOl:10.1177/0954405412472667.

[2] Yang, G. J., Yu, S. H., Zhang, H. C., Chen, G. D. (2009). Construction on the optimization designing system of shearing mechanism of rolling shear. Journal of Machine Design, vol. 29, no. 3, p. 63-66. (in Chinese)

[3] Huang, Q. X., Ma, L. F., Li, J. B. (2008). Principle of asymmetric crank mechanism of new-type rolling shear. Chinese Journal of Mechanical Engineering, vol. 44, no. 5, p. 119-123, DOI:10.3901/JME.2008.05.119. (in Chinese)

[4] Quan, L., Xu, X.Q. (2008). Simulation and test of electrohydraulic servo position and pressure hybrid control principle.
Chinese Journal of Mechanical Engineering, vol. 44, no. 9, p. 100-105 D0I:10.3901/JME.2008.09.100. (in Chinese)

[5] Madani, M., Moallem, M. (2011). Hybrid position/force control of a flexible parallel manipulator. Journal of the Franklin Institute, vol. 348, no. 6, p. 999-1012, D0l:10.1016/j. jfranklin.2011.03.005.

[6] Bessa, W.M., Dutra, M.S., Kreuzer, E. (2010). Sliding mode control with adaptive fuzzy dead-zone compensation of an electro-hydraulic servo-system. Journal of Intelligent and Robotic Systems, vol. 58, no. 1, p. 3-16, D0l:10.1007/s10846009-9342-x.

[7] Kim, J.W., Xuan, D.J., Kim, Y.-B. (2008). Design of a force control system for a dynamic road simulator using QFT. International Journal of Automotive Technology, vol. 9, no. 1, p. 37-43, D0I:10.1007/s12239-008-0005-x.

[8] Tai, N.T., Kha, N.B., Ahn, K.K. (2010). Predictive position and force control for shape memory alloy cylinders. Journal of Mechanical Science and Technology, vol. 24, no. 8, p. 17171728, D0l:10.1007/s12206-010-0504-3.

[9] Zhao, W. Z., Sun, P. K., Liu, S., Lin, Y. (2012). Multi-objective optimization of active steering system with force and displacement coupled control. Journal of Central South University, vol. 19, no. 4, p. 974-981, D0I:10.1007/s11771012-1099-x.

[10] Murakawa, M., Lu, Y. (1997). Precision cutting of sheets by means of a new shear based on rolling motion. Journal of Materials Processing Technology, vol. 66, no. 4, p. 232-239, D0I:10.1016/S0924-0136(96)02529-0.

[11] Lei, J. B., Wang, X. Y., Pi, Y. J (2013). Sliding mode control in position control for asymmetrical hydraulic cylinder with chambers connected. Journal of Shanghai Jiaotong University (Science), vol. 18, no. 4, p. 454-459, D0l:10.1007/s12204013-1419-9.

[12] Huang, F. (2011). The Acceleration and Deceleration Algorithm and Simulation of Position and Pressure Control Conversion Process of Electro-Hydraulic Servo System. Wuhan University of science and technology, HuBei.

[13] Han, H. Y., Wang, J., Wang, J., Huang, Q.X. (2012). Analysis of unsymmetrical valve controlling unsymmetrical cylinder stability in hydraulic leveler. Nonlinear Dynamics, vol. 70, no. 2, p. 1199-1203, D0l:10.1007/s11071-012-0523-y.

[14] Yu, J., Li, Y. (2011). Simulation on electro-hydraulic proportional position control system under pressure boundary conditions. Advanced Materials Research, vol. 186, p. 21-25, DOl:10.4028/www.scientific.net/AMR.186.21.

[15] Yi, J.G. (2015). Modelling and analysis of step response test for hydraulic automatic gauge control. Strojniški vestnik Journal of Mechanical Engineering, vol. 61, no. 2, p. 115-122, D0I:10.5545/sv-jme.2014.2046. 